\title{
Perspectives on Politics: A Political Science Public Sphere
}

\author{
Jeffrey C. Isaac, Editor in Chief with the assistance of James Moskowitz, Managing Editor
}

I am happy to report that Perspectives on Politics continues to thrive. In the Lalmost seven years since we assumed editorial control of the journal, in June 2009, we have succeeded in strengthening journal operations and procedures and in projecting a new and growing excitement about Perspectives and the role it can play in contributing to the invigoration of the discipline.

We have a highly talented, energetic, and well-organized staff, and we have developed a strong set of procedures for dealing with authors, reviewers, and each other. As a consequence we have continued to work efficiently and stay on production schedule with APSA, Cambridge, and the compositors. I continue to receive a great deal of positive feedback from authors and from readers about the journal, its quality, its special sections, and its accessibility and responsiveness. More importantly, we continue to receive a growing flow of manuscripts of an increasingly high quality, from established scholars eager to place their work in our journal and from more junior scholars who regard Perspectives and its mission as hospitable to their view of political science. In the past year we received one fewer than last year's record number of article submissions, and have published a wide range of authors from a variety of institutions.

In 2015 Perspectives published 19 articles (with 30 authors), seven Reflections and Praxis essays (with 15 authors), three Reflections symposia (with 15 contributors), and three book symposia (with 11 contributors), 12 critical dialogues, and 313 book reviews. We thus published the work of over 400 political scientists. If you add to that the number of manuscript reviewers with which we have corresponded, in 2015 the journal networked with more than 1,10o political scientists. Through our extensive and substantive correspondence and through the product of that correspondence-the journal itselfwe believe we are succeeding in our goal of fostering a political science public sphere.

The Appendix to this report includes some basic publication and production data. We will be happy to answer any questions about this data to the best of our ability.
In what follows I would like briefly to outline a range of accomplishments worthy of note, which together help to explain our success thus far. In doing so, I will reiterate some of the themes of last year's report, since they are essential to our ongoing operations, and also since each year new members join the Council, and my goal is to keep every member of the Council maximally informed about our journal operations.

\section{A COLLABORATIVE EFFORT}

Perspectives is a collaborative effort, and the journal works well because it has a terrific staff. James Moskowitz is an exceptional managing editor. He combines business experience, strong communication and computer skills, a real aesthetic sensibility, and the scholarly perspective of an experienced and published political scientist with an MA while also completing a PhD. James has contributed immeasurably to the success of the journal along every dimension, from the efficient operation of the EM system to the journal's terrific new design, and he is responsible for the extraordinary covers we have featured in the past year. James works full-time on the journal. He has already indicated his willingness to continue serving as Managing Editor for the next editorial team if they are so interested; he would be a major asset and would contribute immeasurably to an effective and seamless transition.

James is joined by six equally terrific editorial assistants whose contributions are immense. Brendon Westler and Rafael Khachaturian work on the journal's front end, reading every article submitted for publication, and participating with James and me in weekly "conference reviews" where we decide which pieces to send out for external review. They then divide up labor to find reviewers for the manuscripts and to stay on top of all communication with reviewers. They also work closely with James to prepare for publication those articles eventually accepted for publication. (Rafael also serves as our Social Media Coordinator as a 10-hour a week hourly employee). Peter Giordano, Rachel Gears, Fathima Musthaq, and Katey Stauffer work with James on the
Review section, helping me find reviewers for each book, corresponding with reviewers, and working to move all reviews to publication. Another former editorial assistant, Laura Bucci, regularly attends our meetings, brainstorms with me about ideas, and offers "institutional memory" to our newer assistants. She will officially rejoin our staff next year, replacing Brendon Westler.

The staff works very well together. We meet weekly to discuss all aspects of the journal, to prepare manuscripts for copy editing, and to plan ahead. We also typically have lunch (supplied by me). It is a very upbeat work environment. All editorial assistants are encouraged to take initiative and to make sure that their work on the journal complements their academic work and long-term scholarly plans. And I subsidize every staff member (approximately $\$ 500$ per person) so that the entire staff can attend the annual MPSA meeting and participate in our editorial board meeting. Much of the work of academic journals is done by staff, consisting almost entirely of graduate assistants. I am very proud of my staff, and proud of the work environment we have cultivated in our office.

I am also proud of the scholarly progress that my staff has made in advancing their own intellectual agendas. Last year Margot Morgan secured a tenure-track assistant professor position at Indiana University Southeast; Adrian Florea served as a visiting assistant professor at Oberlin College and was recently hired as a tenure-track assistant professor at University of Glasgow; Brendon Westler recently had a piece published in Journal of the History of Ideas and a second piece published in Review of Politics; Rafael Khachaturian recently published an article in Polity; and our other assistants are also making great progress toward their dissertations. These young scholars do the lion's share of the work of our discipline's journals, and it is very important that their work is recognized as valuable and that it enhances their professional development. Along these lines I note with particular pleasure that Elizabeth Markovits is not simply a current board member who is also the coauthor of a published research article; she is a former 
Perspectives editorial assistant, having worked on the Book Review when it was located at the University of North Carolina. I regard this trajectory as a model for my staff.

\section{EDITORIAL BOARD}

The journal has a terrific editorial board. We stay in fairly regular communication with the board as a whole, and communicate very often with individual board members, to consult on difficult decisions and to seek additional reviews of manuscripts when this becomes necessary. Board members have been very responsive and helpful, and many of them have been proactive in encouraging authors to submit their work for review. I believe that a journal like Perspectives can only succeed if a diverse group of excellent and highly respected political scientists are willing to make a commitment and to link their credibility to the credibility of the journal. Sustaining this kind of connection has been an important accomplishment and it remains an ongoing commitment.

I am proud to say that the entire board that began with my tenure continues to serve, along with some newer and equally exceptional colleagues. (A full list of our board members appears on our masthead, and is included in the Appendix).

\section{WORKING RELATIONSHIPS}

We continue to have excellent working relationships with the principals with whom we work to produce the journal.

- At APSA, we work directly with Barbara Walthall, APSA's journal point person.

- At Cambridge University Press we continue to work smoothly Mark Zadrozny, journals editor; Jonathan Geffner, who is the Cambridge point person on all production issues; and Janice Lazarte, who works to help promote our issues and special articles, and helps us to ungate material. Cambridge continues to be exceptionally wonderful to work with.

- In 2014 the long-time compositor of Perspectives, Beljan, Ltd., went out of business. Perspectives is now being composited by a new company (TNQ), located in India. Both APSA and Cambridge have been extremely professional and supportive. The new company has been terrific to work with.

- James does an excellent job in staying in touch with all of these people, being responsive to their concerns, and obtaining their help when it is necessary. I can't say enough about the synergy between Cambridge and APSA and how essential this kind of relationship is to the success of the journal. We are also fortunate to have the help of two excellent copy editors: Linda Lindenfelser, who worked with Jim Johnson when the journal was at Rochester, and Phyllis Berk. While we do some copy editing in-house, we have budgeted to have almost all of it done externally by experienced professionals. This is important for a journal in which broad intelligibility, and thus excellent prose writing, is essential.

We are also very fortunate to have the exceptional support provided by Indiana University (IU), its College of Arts and Sciences, and its political science department. IU has provided course release for me, and support for graduate assistance for the four years of my tenure as book review editor. It also has housed our editorial office and furnished state-of-the-art computer support. By this June, IU will have supported and housed the journal for 11 years. This support, and the scholarly and collaborative spirit in which it is provided, has been indispensable to the success of the journal. In an age where such support is increasingly hard to come by, this is worth noting.

\section{COMMUNICATION WITH AUTHORS AND REVIEWERS}

We have maintained excellent and efficient communication with authors, reviewers, and people in the field more generally. We try-and almost always succeed-in completing our internal review of each submitted research article within 10 days of submission. We move promptly to identify external reviews for all suitable manuscripts. I also write substantial and constructive letters to every author whose paper we decide not to send out for review. I try to send these letters within 10-14 days of submission, and when there are delays, I try to explain them to authors in personal letters. I have received a great deal of appreciative feedback from many of the authors whose papers we chose not to send out for external review. Frequently, we invite these authors to instead contribute to Perspectives in the role of book reviewers, which they often do. We also stay in close touch with authors through the publishing process, from external review through revision through preparation for publication. Iwrite careful, clear, and substantive letters to each author offering guidance. If there are delays we write to authors explaining them. I write follow-up letters to authors from whom we really wish to see a revised paper, encouraging prompt revision and resubmission. I also write often to scholars in the field, inquiring about interesting-sounding conference presentations, and inviting article submissions. I am especially interested in cultivating connections to junior scholars whose work has merited official recognition or seems particularly interesting. We are always looking to reach out to new authors and readers, and to attract new and exciting work for review and publication. At the same time, all research articles are subject to our strict, double blind external review process.

As a matter of general policy, we prize efficient, prompt, and kind communication. Every letter is an opportunity to explain the journal's distinctive mission and to make a friend for the journal.

In November 2015 I published "Publish, Publish, and Be Yourself: On Being 'Nice' in Political Science” on a political science blog called The Plot. The piece can be found online here: http://www.the-plot.org/2015/11/24/ publish-publish-and-be-yourself-on-beingnice-in-political-science/

In December 2015 I published a piece on "Beyond Rejection" on a political science blog called Duck of Minerva. The piece can be found online here: http://duckofminerva. com/2015/12/beyond-rejection.html.

Both of these pieces provided additional clarification of our editorial philosophy, in addition to drawing more attention to the journal.

We also keep excellent records of all communication. Every official letter is sent through Editorial Manager, and copied to the Perspectives e-mail account and my own e-mail account, and all letters are backed up.

\section{PEER REVIEW PROCESS}

For the past many years, we have worked hard to make our peer review process for all research article submissions more serious and systematic and to make clear to all readers that every single research article published in Perspectives has been through a demanding blind internal review process and then a double-blind external review process. Our review processwhich includes careful editorial selection of reviewers and directions to all authors regarding revisions, and also includes very careful line editing of every sentence by the 
editor in chief, in addition to careful copy editing-is as serious, if not more serious, than that of any other peer-reviewed political science journal.

I believe we have succeeded in this effort.

We thus continue to receive a growing number of excellent article submissions, many of which, it turns out, are authored by top scholars in the field. By being very serious about our review process, we have succeeded in increasing the number of truly excellent articles submitted, and have built the journal's reputation as a peer-reviewed journal, so that increasing numbers of junior colleagues think of Perspectives as a first option for their best work when this work is framed broadly.

Along these lines, I am especially happy to report that the journal has built a very strong queue of accepted articles. Our June 2016 issue is in press; our September issue is completely filled and ready for production and our December 2016 issue is already filled with accepted articles. This queue is growing, and it speaks volumes for the journal moving forward.

\section{JOURNAL THEMATIC FOCUS}

As we have reported in the past, we have become adept at developing a reasonable publication schedule that provides a measure of focus to our planned issues. Our June 2015 issue was a special issue featuring pieces on the past and future of the discipline. (It was the topic of the very successful Perspectives annual theme panel at the 2015 APSA meetings in San Francisco). Our September 2015 issue was a major and widely praised special issue on "the American politics of policing and incarceration." I am pleased to report that we have two exciting forthcoming issues: the June 2016 issue will feature "the politics of labor," and the September 2016 issue will feature articles, essays, and reviews relevant to the November 2016 election.

We are a general journal of political science, and the articles we publish represent the best of what is submitted to us that makes it through our review process. But by thinking strategically about timing and production schedule, proactively soliciting Reflections essays, and developing special Book Review theme sections, we are able to call attention to some of the "big topics" that touch on all areas of political science-as it is our mission to do. I regard this kind of editorial "visioning" and planning as a central aspect of my job as editor in chief of this particular journal.
The themes that I decide to feature are developed on the basis of my own extensive reading, conversations with board members and other colleagues, and extensive staff deliberations. At the same time, I am always listening to and indeed soliciting feedback, from editorial board members and from colleagues more generally, about what we are doing, about themes that are worthy of attention, and about how we can do what we do better.

\section{REVIEW FORMATS AND SECTIONS}

Perspectives seeks to nurture a political science public sphere that allows scholars to move beyond their normal comfort zones and reach broadly, beyond conventional methodological and subfield divides, and to the discipline as a whole. Toward this end, in the past eight years we have instituted a number of innovative formats to our Review section-Book Symposia, Critical Dialogues, creative categorizing of certain books. Two years ago we added an additional innovation: each issue now typically contains, in addition to the "standard" four-subfield sections, a special "theme" section highlighting books that address an important substantive theme irrespective of field or approach.

It is worth underscoring that the overwhelming majority of the book reviews that we publish appear under one of the standard four subfield categories, and that while we have made important innovations in the book review section, the basic mission of the review section remains unchanged: to publish careful, constructively critical, and interesting reviews of political science books that feature important scholarly research and writing.

It is also worth underscoring that every aspect of the Review section-its innovations and its more conventional featuresis designed to serve our journal's core mission, which is the promotion of a political science public sphere. We believe that the book form represents an invaluable genre for the scholarly development of sustained, integrated analyses and arguments, and that scholarly books are thus an essential component of scholarly publishing. We thus seek to highlight the importance of political science books and to feature interesting discussions of books, in the hope that this will help sustain a book culture within political science and the social sciences more generally.

Indeed, one of our goals is to give full due to the entire range of genres and formats in which scholarly work in our discipline is published, from scholarly research articles and reflective essays to books, book reviews and review essays, and dialogues. Perspectives on Politics is a single journal with a single mission that links all sections, and we believe that the integrated character of the journal is one of its great strengths.

\section{EDITORIAL INTRODUCTIONS AND "EXPLAINING" THE JOURNAL}

We continue to work hard to project the journal as an important site of serious thinking about the future and purpose of our discipline. My editor introductions to each issue, composed as titled, synthetic, and thematic essays, represent one part of this effort. Beyond those introductions, I do a significant amount of writing intended to promote the journal and to better explain its distinctive mission to readers and potential readers. See in particular "A Political Science Public Sphere," which was published online at The Plot and can be viewed here: http://www.the-plot. org/2015/10/o1/a-political-science-publicsphere/ (over 220o views).

\section{DA-RT}

I am very proud of the leadership that our journal has taken in resisting the momentum generated on behalf of DA-RT. I have written extensively about this, in a number of widely read pieces cited immediately below. The most important piece was my introduction to the June 2015 issue, "For a More Public Political Science," a 13,000 word essay that was the second-most viewed piece published in an APSA journal in 2015 (since June it has been viewed 18, 691 times). In this piece I did two main things: 1) I explained the reasons why many aspects of DA-RT were both unnecessary and inconsistent with our journal's broad editorial mission, and why Perspectives would never sign on to the DA-RT statement so long as I am its editor-a position supported by the journal's editorial board; and 2) I argued more generally that DA-RT was motivated by a very narrow conception of "public accessibility," and urged a broader and more vigorous disciplinary discussion, both of DA-RT and of the public roles of political science.

I am very proud of the leadership exercised by the journal on this issue, and I believe that our journal's very early and publicly explained position contributed to a great deal of constructive and civil conversation 
within the profession that is still ongoing. Indeed, a number of Perspectives editorial board members were principals of a widely signed petition calling for more deliberation, and subsequently created an important website, Dialogue on DA-RT, which has circulated a wide variety of perspectives on DA-RT and related issues (http://dialogueondart.org).

I have written three things in recent months that have been reposted on The Plot.

- "Further Thoughts on DA-RT" (http:// www.the-plot.org/2015/11/o2/furtherthoughts-on-da-rt/ with over 5000 views)

- "A Broader Conception of Political Science Publicity" (http:/www.the-plot. org/2015/12/o3/a-broader-conceptionof-political-science-publicity-or-why-irefuse-da-rt/)

- "Is More Deliberation about DA-RT Really So Good?" (http://www.the-plot. org/2016/01/23/is-more-deliberationabout-da-rt-really-so-good/)

\section{COMMITMENT TO RESEARCH TRANSPARENCY}

While the journal has refused to adopt the DA-RT guidelines, it has also been very clear, and very public, about its long-standing commitment to research transparency broadly construed, and in November, 2015 we posted a statement on "transparency" explaining our policies on the Dialogue on DA-RT website here: http://dialogueondart.org/2015/11/3o/perspectives-onpolitics-editors-share-policy-establishedin-2009/

\section{STATEMENT ON SCHOLARLY RECOGNITION}

More importantly, Perspectives, with the full support of the editorial board, issued a broader Statement on Scholarly Recognition that linked support for scholarly honesty to support for greater inclusivity regarding citation practices and other forms of scholarly professional development. This has been published on APSA's website here: http://www.apsanet.org/ LinkClick.aspx?fileticket=_ossKGv37eo\%3 $\mathrm{d} \&$ portalid $=54$

I personally regard this statement as one of the most important things the journal has done under my editorship.

Our journal has an extraordinary editorial board that is very diverse and that includes a large number of women scholars who are committed, through their scholarship and their professional involvements, to a political science that is maximally inclusive of women, people of color, and LGBT colleagues.
The board took up a serious discussion of gender bias in citation practices over two years ago. And last fall the board voted unanimously in favor of an explicit policy that "nudges" colleagues to be attentive to inclusivity. I believe our journal is the first major political science journal to adopt, announce, and publicize a policy on this important question. This policy is fully consistent with our commitment to highest forms of scholarly excellence and our commitment to a problemcentered political science. It is also continuous with the fact that our journal is the only journal in the history of APSA journal's to have published an entire issue centered on the theme of gender. Indeed, our journal has published two such issues, in March, 2010 and in March, 2014.

\section{SOCIAL MEDIA CAMPAIGN}

Last year our journal was encouraged by APSA to develop a systematic social media campaign. I am thrilled to report that we have both developed and initiated a social media campaign, and it is flourishing.

The campaign is spearheaded by Rafael Khachaturian, our social media coordinator. Rafael is a senior doctoral student who has worked on staff as a Book Review editorial assistant for three years, and who recently began working as an article editorial assistant. In June 2014 he assumed his new position, in which he works 10 hours per week as an hourly employee. Rafael, working in tandem with James Moskowitz, has: a) created and maintained a Perspectives Twitter account; b) tweeted regularly about Perspectives articles, essays, and reviews that relate to items "in the news"; c) posted announcements about the journal on Facebook; and, most importantly d) worked with Janise Lazarte of Cambridge University Press to regularly ungate Perspectives articles in connection with special promotions and press releases and especially in conjunction with the blogging of our authors.

Publicizing the journal on social media has allowed us to cultivate a broad audience and to promote our quarterly issues extending beyond their previous "shelf life." Our excellent working relationship with Cambridge has allowed us to ungate many articles, and usually all parts of a given issue are made openly accessible to the public at some point over the time it takes for a forthcoming issue to appear. Our September, 2015 issue on the politics of policing and incarceration was made entirely accessible at once, which was instrumental in helping it gain a wide amount of publicity. In addition, our ungating of the book review sections, apropos of our belief in the special and distinctive mission that books play for our discipline, are regularly met with enthusiasm by our audience.

Currently we are also experimenting with a new form of promoting our content by "packaging" together certain articles that address the same topic. To commemorate the five-year anniversary of the Arab Spring in January, 2016, we gathered a number of our past articles on the topic, had them ungated, and coordinated with Cambridge to notify over 1,200 subscribers of

Table 1

\section{Blog Posts by Perspectives Authors in 2015 AUTHORS POST TITLE}

\section{OUTLET}

\begin{tabular}{|c|c|c|}
\hline $\begin{array}{l}\text { Mary Katzenstein and Mau- } \\
\text { reen Waller }\end{array}$ & $\begin{array}{l}\text { "Phone calls won't cost up to } \$ 14 \\
\text { a minute anymore but here's how } \\
\text { prisoners' families are still being } \\
\text { fleeced" }\end{array}$ & Monkeycage \\
\hline Lynda Dodd & $\begin{array}{l}\text { "Civil rights suits against the police } \\
\text { are an essential tool for enforcing } \\
\text { the Constitution. But cops rarely } \\
\text { pay and settlements don't lead to } \\
\text { change." }\end{array}$ & $\begin{array}{l}\text { US Centre (London School } \\
\text { of Economics) }\end{array}$ \\
\hline $\begin{array}{l}\text { Lindsey Benstead, Amaney } \\
\text { Jamal, and Ellen Lust }\end{array}$ & $\begin{array}{l}\text { "Why Tunisians (don't) Vote for } \\
\text { Women" }\end{array}$ & Monkeycage \\
\hline $\begin{array}{l}\text { Amaney Jamal, Robert } \\
\text { Keohane, David Romney, } \\
\text { and Dustin Tingsley }\end{array}$ & $\begin{array}{l}\text { "Anti-Americanism in Arabic Twitter } \\
\text { discourses is driven by perceptions } \\
\text { of U.S. impingement in the region" }\end{array}$ & $\begin{array}{l}\text { US Centre (London School } \\
\text { of Economics) }\end{array}$ \\
\hline $\begin{array}{l}\text { Matt Grossman and David } \\
\text { Hopkins }\end{array}$ & $\begin{array}{l}\text { "More proof that Republicans are } \\
\text { from Mars and Democrats are from } \\
\text { Venus" }\end{array}$ & Monkeycage \\
\hline $\begin{array}{l}\text { Sarah Baurle Danzman and } \\
\text { Kindred Winecoff }\end{array}$ & $\begin{array}{l}\text { "This is why you shouldn't blame } \\
\text { China for the havoc in the markets" }\end{array}$ & Monkeycage \\
\hline
\end{tabular}


our content alerts of this initiative. The email promotion that was sent out can be viewed here:http://journals.cambridge.org/action/dis playSpecialPage pageId $=7864$.

This initiative resulted in approximately $37 \%$ of the emails being opened, and $10 \%$ of the article links being clicked. The Cambridge team informed us that these figures indicate a successful promotion, and we will be continuing this initiative. In June, 2016 we will put together a similar promotion on the topic of democracy and oligarchy in American politics, in advance of our September issue on the election.

In addition to his coordination with Janise Lazarte and Cambridge, Rafael is also in communication with the team behind PS Now, who have been happy to feature our ungated content on their website, www. politicalsciencenow.com, and to tweet out our journal content on the official Twitter handle of APSA, @APSAtweets.

We have been actively encouraging our authors to write blog posts, and have worked with them to time the ungating of their pieces. Table 1 includes a sampling of posts over the past year.

\section{Appendix}

\section{PERSPECTIVES ON POLITICS EDITORIAL BOARD}

Edwina Barvosa, University of California, Santa Barbara Richard Battistoni, Providence College

Michael Bernhard, University of Florida Charli Carpenter, University of Massachusetts, Amherst Daniel Drezner, Fletcher School, Tufts University

Henry Farrell, George Washington University Page Fortna, Columbia University

Ange-Marie Hancock, University of Massachusetts, Amherst Marc Morjé Howard, Georgetown University

Mala Htun, University of New Mexico Bryan Jones, University of Texas at Austin Stathis Kalyvas, Yale University Mary Katzenstein, Cornell University

\section{Decision Rates 2015}

Decision Rates for 2015 ( $n=259)$

\section{SUBMISSIONS}

\begin{tabular}{ll}
\hline Decline external review & $65 \%$ \\
\hline Review externally & $35 \%$
\end{tabular}

FIRST DECISION UPON EXTERNAL REVIEW

\begin{tabular}{lc}
\hline Decline & $63 \%$ \\
\hline Major revision & $28 \%$ \\
\hline Minor revision & $9 \%$ \\
\hline Conditional accept & $0 \%$
\end{tabular}

FINAL DECISION TO DATE

\begin{tabular}{lc}
\hline Accept & $6 \%$ \\
\hline Do not externally review & $65 \%$ \\
\hline Decline upon review & $19 \%$ \\
\hline Revise & $5 \%$ \\
\hline Under Review (V1-R1) & $5 \%$ \\
\hline With Editor (R2+) & $1 \%$
\end{tabular}

Timothy Kaufman-Osborn, Whitman College Mark Lynch, George Washington University Samantha Majic, John Jay College, CUNY Elizabeth Markovits, Mount Holyoke Melissa Nobles, Massachusetts Institute of Technology Paul Pierson, University of California at Berkeley Andrew Sabl, University of California at Los Angeles James Scott, Yale University Joe Soss, University of Minnesota Paul Staniland, University of Chicago Dara Strolovich, University of Minnesota Lisa Wedeen, University of Chicago

\section{Decision Rates 2010-2014 SUBMISSIONS}

\begin{tabular}{lc}
\hline Decline external review & $59 \%$ \\
\hline Review externally & $41 \%$
\end{tabular}

FIRST DECISION UPON EXTERNAL REVIEW

\begin{tabular}{lc}
\hline Decline & $62 \%$ \\
\hline Major revision & $24 \%$ \\
\hline Minor revision & $10 \%$ \\
\hline Conditional accept & $3 \%$
\end{tabular}

FINAL DECISION TO DATE

\begin{tabular}{|c|c|}
\hline Accept & $8 \%$ \\
\hline Do not externally review & $59 \%$ \\
\hline Decline upon review & $23 \%$ \\
\hline Revise & $5 \%$ \\
\hline Under Review (V1-R1) & $4 \%$ \\
\hline With Editor (R2+) & $1 \%$ \\
\hline \multicolumn{2}{|c|}{$\begin{array}{l}\text { Note: A comparison of data from the last volume-year against the pre- } \\
\text { vious five volume years indicates a slight uptick in the percentage of } \\
\text { manuscripts declined for external review. Other decision rates remain } \\
\text { relatively steady. Total article submissions were consistent with the } \\
\text { prior year, consolidating gains from }(2014=260)(2013=213)(2012=200) \\
(2011=195)(2010=185)(2010-2014 n=1053) \text {. (Reflections pieces are } \\
\text { excluded from data.) }\end{array}$} \\
\hline
\end{tabular}




\section{BOOK REVIEW}

The Perspectives on Politics Book Review received over 1250 books in 2015 and identified nearly 400 of them for review or treatment in one of our special formats. We contacted over 1200 potential review authors, over 350 of which agreed to write a review, author a review essay, participate in a critical dialogue, or contribute to a book symposium. (Note: some of these have yet to appear in our pages.) Compared to the prior volume year, the number of reviews and number of books treated rose $17 \%$.

Reviews, Books Treated, and Authors Featured by Section, 2014 REVIEWS

BOOKS TREATED

BOOK AUTHORS

\begin{tabular}{lccc}
\hline Volume 13 Totals & 268 & 313 & 403 \\
\hline SECTIONAL SUBTOTALS & & & 87 \\
\hline Political Theory & 70 & 54 & 98 \\
\hline American Politics & 52 & 99 & 77 \\
\hline Comparative Politics & 82 & 64 & 134 \\
\hline International Relations & 55 & 84
\end{tabular}

\section{SPECIAL SECTION}

(Modernization) 9

9

10

Note: Data in the table above reflect books treated in standard (single, double, and triple) reviews. They do not include symposia, review essays, etc. 